\title{
Rates of immunization against pandemic and seasonal influenza in persons at high risk of severe influenza illness: a cross-sectional study among patients of the French Sentinelles general practitioners
}

Ludivine Privileggio $^{1,2^{*}}$, Alessandra Falchi ${ }^{1,2,3}$, Marie-Lise Grisoni ${ }^{1,2}$, Cécile Souty ${ }^{1,2}$, Clément Turbelin ${ }^{1,2}$, Laure Fonteneau, ${ }^{4}$, Thomas Hanslik ${ }^{1,2}$ and Solen Kernéis ${ }^{1,2}$

\begin{abstract}
Background: Three main categories of persons are targeted by the French influenza vaccination strategy: all persons aged 65 years or over, those aged less than 65 years with certain underlying medical conditions and health care workers. The main objective of this study was to estimate rates of influenza immunization in these target groups attending a medical consultation for two consecutive influenza seasons: 2009-2010 (seasonal and pandemic vaccines) and 2010-2011 (seasonal vaccine).

Methods: A standardized questionnaire was mailed to 1323 general practitioners (GPs) of the Sentinelles Network, collecting data on all patients seen on a randomly assigned day. For every patient, following information was collected: age, gender, BMI, presence of any medical condition that increases risk of severe influenza illness, and vaccination status for the three vaccines mentioned.

Results: Two hundred and three GPs agreed to participate and included 4248 patients. Overall, in persons with high risk of severe influenza, the estimated vaccine coverages (VC) were $60 \%,(95 \% \mathrm{Cl}=57 \% ; 62 \%)$ for the seasonal vaccine in 2010-2011, 61\% (59\%; 63\%) for the seasonal vaccine in 2009-2010 and 23\% (21\%; 25\%), for the pandemic vaccine in 2009-2010. Among people aged 65 years and over ( $\mathrm{N}=1259,30 \%)$ VC was estimated for seasonal vaccines at 72\% (70\%; 75\%) in 2010-2011 and 73\% (71\%; 76\%) in 2009-2010, and 24\% (22\%; 26\%) for the pandemic vaccine. The lowest seasonal VC were observed in younger persons $(<65$ years) with underlying medical conditions, in particular pregnant women $(<10 \%)$ and overweight persons $(<30 \%)$.
\end{abstract}

Conclusions: Our study shows that influenza vaccination coverage among patients of the French Sentinelles general practitioners remains largely below the target of 75\% defined by the 2004 French Public Health Law, and underscores the need for the implementation of public health interventions likely to increase vaccination uptake.

Keywords: Vaccination, Influenza, General practitioners, Sentinelles network, Pregnancy, Obesity

\footnotetext{
* Correspondence: privileggio@u707.jussieu.fr

${ }^{1}$ INSERM, UMR-S 707, Paris F-75012, France

2UPMC Université Paris 06, UMR-S U707, Paris F-75012, France

Full list of author information is available at the end of the article
} 


\section{Background}

In France, seasonal influenza immunization is recommended to all persons aged $\geq 65$ years and those with underlying medical conditions that increase their risk for influenza disease or complications [1]. Before 2010, patients with severe bronchopulmonary, cardiac, renal disease, sickle cell disease/ thalassemia, diabetes mellitus, or any immune disorder (HIV infection, immunosuppressive drugs, cancer ...) were targeted by French immunization recommendations [2]. Since 2010, pregnant women (at any trimester) and overweight persons $(\mathrm{BMI} \geq 30)$ have been added to the list of patients that should receive the monovalent influenza $\mathrm{A}$ (H1N1) 2009 vaccine and subsequently, the seasonal trivalent vaccine yearly [3]. Every year in France, people targeted by seasonal influenza immunization receive an invitation from health authorities to get a free-of-charge vaccine, administered by their General Practitioner (GP). Despite this large national vaccination campaign, rates of immunization against seasonal influenza remain weak: the global vaccination coverage (VC) for the target population was $51 \%$ in $2007,56 \%$ in 2008 and $57 \%$ in 2009 , as estimated by the National Health Insurance [4]. To our knowledge there is no data in the literature on detailed immunization rates among at-risk populations in general practice since the influenza pandemic occurred. The objectives of this crosssectional study were 1) to describe age distribution and risk factors of severe influenza illness in patients seen on a given day by French GPs, 2) to estimate influenza immunization rates for two consecutive seasons (20092010 and 2010-2011), and 3) to identify predictors of seasonal vaccination in target groups.

\section{Methods}

\section{Study design}

We conducted a cross-sectional study among GPs of the French Sentinelles Network, a computerized diseasesurveillance system with active volunteer physicians located throughout mainland France, accounting for $2 \%$ of the whole population of French GPs [5]. All 1323 GPs of the network were contacted by email and invited to participate to the study in May 2011. A day of participation was randomly assigned to each GP who agreed to participate and randomization was balanced to reflect the distribution of the usual days of consultation from Monday to Saturday, as declared by participants.

\section{Data collection}

For every patient presenting on a given day at their practice, participating GPs were asked to fill out a standardised questionnaire on age, gender, vaccination status against seasonal influenza (in 2009-2010 and 2010-2011), pandemic influenza in 2009-2010, and presence of risk factors for severe influenza illness, as defined by French health authorities (Table 1). Data on both chronic conditions and immunization status were reported by the GPs without any written confirmation. Data were obtained either by asking to the patient and/or using data from their medical records.]

In addition, data were collected on age, gender, region of exercise for participating GPs. Regions of exercise were categorised in rural or urban areas according to the mean number of inhabitants (urban municipalities are municipalities without continuous built area of 2000 inhabitants, and those with less than half of the municipal population is in an area of continuous built, as defined by the French Institute of Demography [6]). GPs participating to the study were compared to the whole population of French GPs, based on national data [7] on age, gender, geographical area and type of practice (group or single medical practice).

\section{Statistical analysis and sample size calculations}

Previous studies of the Sentinelles Network estimated that on a normal day of consultation, GPs would see an average of 20 patients [8]. With a response rate of $20 \%$, we calculated that we could include approximately 5,300 patients and estimate rates of immunization as low as $30 \%$ with an accuracy of $5 \%$.

Results are expressed as the median [Interquartile Range] for continuous variables and N (\%) for categorical variables. Immunization rates are given with their 95\% confidence intervals $(95 \% \mathrm{CI})$. Predictors of immunization against seasonal influenza in 2010-2011 were studied by fitting generalized linear models with random intercept to the data. Vaccination against influenza in 2010-2011 was the response variable and 'GP' effect was regarded as a random effect. Variables analysed in the univariate analysis were: age, gender, vaccination against seasonal influenza in 2009-2010, vaccination against pandemic influenza in 2009-2010, and number of individual risk factors for severe influenza illness (taken as $<1$ or $\geq 2$ ). Factors achieving a $p$-value $<0.20$ in the univariate analysis were included in the multivariate analysis. A backward stepwise variable selection procedure was used to remove factors with $p$-value $>0.05$. Statistical analysis was performed using the $\mathrm{R}$ software version 2.13 ( $\mathrm{R}$ Development Core Team, R Foundation for Statistical Computing, Vienna, Austria, http://www.r-project.org).

\section{Ethics}

The protocol was conducted in agreement with the Helsinki declaration. The protocol was approved by the ethical committee (CPP Ile de France V). We obtained authorization from the French Data Protection Agency (CNIL, registration number \#471393) and all data transmitted for statistical analysis were anonymous. Verbal non-opposition was obtained. If a child was selected, non-opposition for participation in the study was requested from a parent (or legal guardian). 
Table 1 People targeted by influenza vaccination in 2010-2011, according to French health authorities

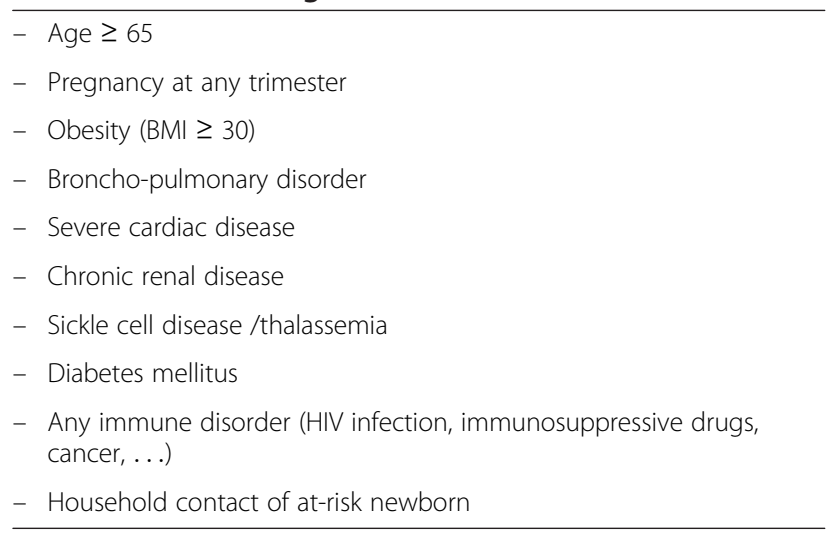

\section{Results}

Practitioners

Of 1,323 GPs of the Sentinelles Network solicited by email in May 2011, 262 agreed to participate (20\%), and 203 (77\%) returned their questionnaire. From June to September 2011, 203 GPs included 4248 patients.

One hundred and seventy four GPs (86\%) were male. Their median age was 55 [Interquartile Range, IQR = 51-59] at the time of the study, and most ( $\mathrm{N}=160,79 \%)$ were aged $>50$ years. All administrative regions of metropolitan France were represented. One hundred and thirty three (67\%) GPs were working in rural areas, and 86 (52\%) belonged to group medical practices. On day of participation, each GP had included 20 patients (median, IQR = 15-25). Participating GPs were comparable to the whole population of French GPs with respect to age (mean age 52 years in both, Student test p-value, $p=0.86$ ), areas and type of practice but there was a higher proportion of men in our sample ( $86 \%$ and $71 \%$ respectively, Chi-2 test p-value $<0.0001)$.

\section{Patients}

Demographical and clinical data of patients are displayed in Table 2. Most patients were women (56\%) and their median age was 50 [IQR=27-68]. Of 4,248 patients included, 1,827 (43\%) were targeted by influenza vaccination, either because of age $(\geq 65, N=1259)$ or the presence of an individual risk factor of severe influenza disease $(\mathrm{N}=568)$ (Table 2). The most represented individual risk factor was obesity $(\mathrm{N}=573,14 \%)$, followed by diabetes mellitus $(\mathrm{N}=361,9 \%)$, severe cardiac disease $(\mathrm{N}=281,7 \%)$, and chronic bronchopulmonary diseases $(\mathrm{N}=243,6 \%)$. Other risk factors were less represented: 5 $(<1 \%)$ patients had chronic renal disease and 44 women were pregnant. Around $2 \%(\mathrm{~N}=64)$ of study patients had chronic immune suppression, either due to HIV infection $(\mathrm{N}=22,<1 \%)$ or other medical conditions such as active solid cancer $(\mathrm{N}=23)$, long term corticosteroid therapy and/or other immunosuppressive drugs for autoimmune diseases $(\mathrm{N}=13)$, malignant hemopathies $(N=9)$, chronic liver diseases $(N=5)$, or solid organ transplantation $(\mathrm{N}=2)$.

\section{Seasonal vaccine}

Overall rates of immunization against seasonal influenza were $32 \%$, (95\%CI: 30\%; 33\%) in 2009-2010 and 30\% $(95 \%$ CI: $28 \%$; $31 \%)$ in $2010-2011$ (chi-square p-value = 0.06 , Table 3 ). Age distributions were not statistically different between the two seasons $(p=0.06)$ (Figure 1). Rates of immunization in patients aged $\geq 65$ were $72 \%$ (95\%CI: 60\%; 81\%) in 2009-2010 and 73\%, (95\%CI: 62\%; $81 \%$ ) in $2010-2011$ (p-value $=0.47$ ). For both seasons,

Table 2 Characteristics of patients included, $\mathbf{N}(\%)$ or median (min -max)

\begin{tabular}{lc}
\hline & Patients included (N=4248) \\
\hline Female & $2373(56 \%)$ \\
Age in years & $50(<1-103)$ \\
Age $\geq 65$ & $1259(30 \%)$ \\
Age $<65$ and at least one individual risk factor & $568(13 \%)$ \\
$\quad$ Pregnancy & $44(1 \%)$ \\
Obesity & $317(7 \%)$ \\
Chronic bronchopulmonary disease & $117(3 \%)$ \\
Severe cardiac disease & $48(1 \%)$ \\
Chronic renal disease & $5(<1 \%)$ \\
Sickle cells/ thalassemia & $2(<1 \%)$ \\
Diabetes mellitus & $129(3 \%)$ \\
HIV infection & $18(<1 \%)$ \\
Other immunosupression & $24(<1 \%)$ \\
Total patients targeted by vaccine recommendations & $1827(43 \%)$ \\
\hline
\end{tabular}


Table 3 Vaccination coverage in $\%(95 \% \mathrm{Cl})$ for three influenza vaccines

\begin{tabular}{|c|c|c|c|}
\hline & $\begin{array}{c}\text { Seasonal vaccine } \\
2010-2011\end{array}$ & $\begin{array}{c}\text { Seasonal vaccine } \\
2009-2010\end{array}$ & $\begin{array}{c}\text { Pandemic vaccine } \\
2009-2010\end{array}$ \\
\hline Patients targeted by vaccine recommendations $(\mathrm{N}=1827)$ & $60(57-62)$ & $61(59-63)$ & $23(21-25)$ \\
\hline Age $\geq 65(\mathrm{~N}=1259)$ & $72(70-75)$ & $73(71-76)$ & $24(22-26)$ \\
\hline Obesity $(\mathrm{N}=256)$ & $75(70-80)$ & $76(71-81)$ & $29(24-35)$ \\
\hline Severe cardiac disease $(\mathrm{N}=233)$ & $83(78-88)$ & $85(81-90)$ & $32(26-38)$ \\
\hline Diabetes mellitus( $(\mathrm{N}=232)$ & $81(76-86)$ & $81(76-86)$ & $35(28-41)$ \\
\hline Chronic bronchopulmonary disease $(\mathrm{N}=126)$ & $87(81-93)$ & $87(81-93)$ & $32(23-40)$ \\
\hline Chronic renal disease $(\mathrm{N}=31)$ & $90(80-100)$ & $90(80-100)$ & $23(8-39)$ \\
\hline HIV infection $(\mathrm{N}=4)$ & $100(100-100)$ & $75(33-100)$ & $67(13-100)$ \\
\hline Other immunosupression ( $\mathrm{N}=18)$ & $78(59-97)$ & $78(59-97)$ & $22(3-41)$ \\
\hline Age $<65$ and $\geq 1$ individual risk factor $(\mathrm{N}=568)$ & $32(28-36)$ & $34(30-38)$ & $21(17-24)$ \\
\hline Obesity $(\mathrm{N}=317)$ & $25(20-30)$ & $27(22-32)$ & $18(14-22)$ \\
\hline Severe cardiac disease $(\mathrm{N}=48)$ & $43(28-57)$ & $47(33-61)$ & $32(19-45)$ \\
\hline Diabetes mellitus( $(\mathrm{N}=129)$ & $53(45-62)$ & $57(49-66)$ & $25(17-32)$ \\
\hline Chronic bronchopulmonary disease $(\mathrm{N}=117)$ & $41(32-50)$ & $44(35-53)$ & $24(17-32)$ \\
\hline Chronic renal disease $(\mathrm{N}=5)$ & $75(33-100)$ & $75(33-100)$ & $50(1-99)$ \\
\hline HIV infection ( $N=18)$ & $67(45-88)$ & $61(39-84)$ & $33(12-55)$ \\
\hline Other immunosupression ( $\mathrm{N}=24)$ & $52(32-73)$ & $57(36-77)$ & $30(12-49)$ \\
\hline Pregnancy $(\mathrm{N}=44)$ & $5(0-11)$ & $7(0-14)$ & $7(0-15)$ \\
\hline Household contact of at-risk newborn $(\mathrm{N}=46)$ & $37(23-52)^{*}$ & $30(17-44)^{*}$ & $21(9-34)^{*}$ \\
\hline
\end{tabular}

*Missing data: 812.

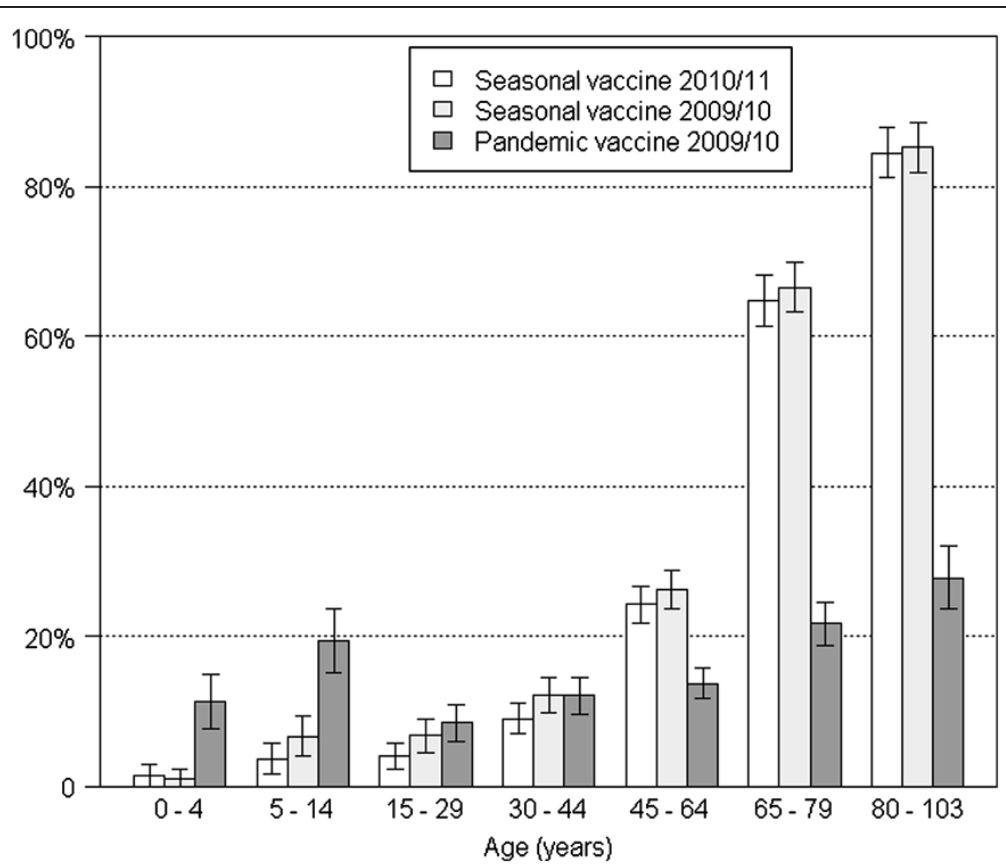

Figure 1 Rates of immunization by age group. Bars present the rates of immunization for three influenza vaccines (seasonal 2009-2010 seasonal 2010-2011 and pandemic), and their 95\%Cl. 
the highest rates of immunization against seasonal influenza were observed in adults aged $\geq 65$ with at least one underlying medical condition, ranging from $75 \%$ to $100 \%$ depending on the risk factor.

Conversely, VC were much lower in $<65$ at-risk adults. Only 34\% (95\%CI: $30 \%$; $38 \%$ ) and 32\% (95\%CI: $28 \%$; $36 \%$ ) had been vaccinated against seasonal influenza in 2009-2010 and 2010-2011 respectively. In the three most represented risk factors among patients aged $<65$ (obesity, chronic bronchopulmonary disease and diabetes mellitus), VC hardly reached $53-57 \%$ in diabetic patients, $41-44 \%$ in those with pulmonary disorder, and less than $30 \%$ in overweight persons. In patients with chronic immune suppression, rates of immunization were slightly higher: $52-67 \%(\mathrm{~N}=42)$. On the other hand, less than $5 \%$ of the forty four pregnant women were vaccinated.

In the univariate analysis, factors associated with immunization against seasonal influenza in 2010-2011 in target groups were: to have received seasonal influenza vaccine in 2009-2010 (OR=220.0, 95\%CI: 131.7; 369.8 ), to have received pandemic influenza vaccine in 2009-2010 (OR=9.9, 95\%CI: 6.9; 14.4) and to have $\geq 2$ individual risk factors for severe influenza illness $(\mathrm{OR}=1.8,95 \% \mathrm{CI}: 1.4 ; 2.4)$. These three predictors remained significantly associated with immunization in 2010-2011 in the multivariate analysis $(\mathrm{OR}=321.4$ (95\%CI: $221.7 ; 465.9) ; 1.9$ (95\%CI: $1.3 ; 2.7)$ and $2.9(95 \%$ CI: 1.7 ; 4.7) respectively).

\section{Pandemic vaccine}

The overall pandemic VC was estimated at 16\% (95\%CI: $15 \% ; 17 \%$ ) in our sample and reached $23 \%$ (95\%CI: $21 \%$; $25 \%$ ) in individuals with risk factors for severe influenza illness. Rates of immunization were higher in children aged $<15$ than that observed for seasonal vaccines ( $\mathrm{p}$-value $<10^{-5}$ for both vaccines), reaching $11 \%$ (95\%CI: $8 \% ; 15 \%)$ in the $0-5$ years and $19 \%$ (95\%CI: $15 \%$; $24 \%$ ) in the $5-14$ years (Figure 1). However, as compared to seasonal vaccines, pandemic immunization rates in adults aged $\geq 65$ years as well as those $<65$ with one risk factor were low. For example in patients aged $>65$ with cardiac disease, VC were of $32 \%$
(95\%CI: $26 \%$; 38\%) for pandemic vaccine as compared to $85 \%$ (95\%CI: $81 \%$; $90 \%)$ for the seasonal vaccine on the same season.

\section{Discussion}

Our estimates of $\mathrm{VC}$ against seasonal and pandemic influenza were generally comparable or higher than that previously reported in certain categories of patients, such as those aged 65 and over, or with chronic cardiac, pulmonary diseases or diabetes mellitus.

Our estimates of VC for the 2010-2011 season were comparable to those estimated by the French National Health Insurance for subjects below 65 years with chronic conditions; but higher for persons aged 65 years and over [9], as shown in Table 4. In patients aged $\geq 65$, who accounted for around one third of our sample, VC were above $70 \%$ for the influenza seasonal vaccines for both seasons, similar (76\%) to that reported in another study among patients of the French GPs in 2006-2007 season [10], but substantially higher than $\mathrm{VC}$ value (61\%) estimated in general population aged 65 and over in France in 2010-2011 season [11], in Spain in 20102011 (59\%) and 2009-2010 (63\%) [12], and in the United States in 2009-2010 (69\%) [13]. In our sample of cardiovascular disease sufferers, VC varied notably between the two age groups: $43-47 \%$ below the age of 65 , and $83-85 \%$ above 65. In comparison, in Spain, in 2003, vaccination coverages were of $17 \%$ in people aged $16-49,34 \%$ in those aged $50-64$ and $69 \%$ in patients aged 65 years and over [14]. In the USA, these proportions for the 19992000 influenza season were of $23 \%$ (95\% CI, $18 \%-27 \%$ ), $49 \%$ (95\% CI, 44\%-54\%), and 77\% (95\% CI, $74 \%-80 \%$ ) respectively [15]. Similar features were observed for patients with chronic respiratory diseases: whereas $\mathrm{VC}$ were above $85 \%$ in those aged 65 and over, younger patients were less likely to be vaccinated (VC: 41-44\%), although chronic bronchopathy is a well-documented risk factor for severe influenza. A Spanish study showed that influenza vaccination coverage among subjects with chronic respiratory diseases in 1993, 1995-1997 and 2001 were $45 \%, 46 \%$ and $44 \%$, respectively and variables that increased the likelihood of having been vaccinated

Table 4 Vaccination coverages in \% $(95 \% \mathrm{Cl})$ for seasonal influenza vaccine in France in 2010/2011, as estimated in three different studies

\begin{tabular}{|c|c|c|c|}
\hline \multirow[t]{2}{*}{ Methodology } & \multirow[t]{2}{*}{ Origin of data } & \multicolumn{2}{|c|}{$\begin{array}{c}\text { VC for seasonal influenza } \\
\text { vaccine in 2010/2011 }(95 \% \mathrm{Cl}\end{array}$} \\
\hline & & $\begin{array}{l}\text { 6m-64yo with } \\
\text { chronic illness }\end{array}$ & $\geq 65 y o$ \\
\hline Administrative data & CNAMTS administrative data (general population) [9] & $33.1 \%$ & $54.0 \%$ \\
\hline Cross-sectional national telephone survey & $\begin{array}{l}\text { French Institute for public health surveillance's survey } \\
\text { (general population) [11] }\end{array}$ & $46.6 \%(39.7-53.6)$ & $\begin{array}{c}61.0 \% \\
(56.7-65.0)\end{array}$ \\
\hline $\begin{array}{l}\text { Standardized survey on a randomly assigned single day in } \\
\text { general practice }\end{array}$ & $\begin{array}{c}\text { Patients of GPs of the French Sentinelles Network } \\
\text { (present study) }\end{array}$ & $32 \%(28-36)$ & $72 \%(70-75)$ \\
\hline
\end{tabular}


were: higher age, presence of another concomitant chronic disease, poor perception of health, non-smoker status, and being married $[16,17]$. Yet, another Spanish study was conducted in early 2003 in population over 40 years of age with Chronic Obstructive Pulmonary Disease and treated at primary-care centers. Over 10000 patients, 87\% reported having been vaccinated in the most recent influenza campaign, therefore a rate comparable to that found in our study in the $\geq 65$ only. Beside socio-demographic data, health-status related variables, and lifestyles analysis, authors found that the factor that was most strongly associated with influenza vaccination was a precedent vaccination against pneumococcal infection [18]. Similarly, in diabetic patients, we report seasonal vaccine coverages of $53-57 \%$ in $<65$ and $81 \%$ in $\geq 65$ patients, whereas in Spanish diabetic adults, VC were estimated at $57 \%$ in 2003 [19] and only $34 \%$ among those aged $<65$ years in $2009-2010$ [20].

Overall rate of immunization against pandemic influenza $A(H 1 N 1) 2009$ was very low in our sample $(16 \%$, 95\% CI: 15\%; 17\%), higher than national estimates in the general population $(<8 \%)$ [21], but close to that $(17 \%)$ reported in another French cross-sectional study conducted among GPs in spring 2010 (the MOTIVAC study) [22]. These results likely reflect the public perception of low risk from the disease and the negative impact of controversies concerning the safety and quality of the pandemic vaccines [23,24]. Distinction must be made between GP involvement in a pandemic context and GP involvement in a seasonal context. Indeed, in France in the context of the H1N1 pandemic, their role was relegated to second place in favor of mass vaccination in health centers open for the event. This campaign was considered as a failure because a very small part of the population joined the vaccination while logistical and financial efforts to organize it were particularly important. Hence the importance of the involvement of the specialists in the promotion of vaccination in patients with specific risk factors (such as pregnancy, severe pulmonary, cardiac and renal diseases).

In our study population, $14 \%$ of patients were obese, and $11 \%$ in those aged $<65$. More than $50 \%$ of them had no other risk factor for severe influenza. Obese poorly vaccinated were those under $<65$ years for seasonal flu and all subjects of this sample for pandemic influenza. It must be noted that there is no data in the literature on the obese influenza vaccination coverage. Sample sizes were low in other target groups, thus estimates of $\mathrm{VC}$ should be interpreted with caution in these categories. Forty four pregnant women could be evaluated for both influenza seasons in our study population. VC for seasonal and pandemic influenza vaccines were particularly low (5-7\%). In the United States, were influenza vaccination is routinely recommended in all pregnant women,
$\mathrm{VC}$ was estimated at $51 \%$ for seasonal influenza vaccine and $47 \%$ for the pandemic influenza vaccine in 20092010 [25]. Similarly, a large number of pregnant women in the Netherlands reported to be vaccinated against 2009 influenza A (H1N1): 63\% (2993 respondents/ 14529 patients invited to complete an internet survey) [26]. Influenza vaccination of pregnant women was a focus of public health efforts during the 2009-10 season in France. Before this season, vaccine recommendations didn't apply to them if they had no identified risk factor for severe influenza. However, the VC reported here suggest a poor adherence to influenza vaccination in this category, as confirmed in another large cohort of French pregnant women in 2009 [27], were $29 \%$ of women reported to be vaccinated against pandemic influenza. It might be related to the physicians and patients insufficient information about the safety of the pandemic vaccine [28].

In the 18 patients living with HIV aged 65 or less, 61$67 \%$ declared being vaccinated against seasonal and $33 \%$ against pandemic $2009 \mathrm{~A} / \mathrm{H} 1 \mathrm{~N} 1$ influenza. In the US influenza vaccination coverage in HIV-Infected patients increased from $29 \%$ in the 1990 to $42 \%$ in the 2002 season [29]. A French study reported comparable A/H1N1 vaccine coverage (44\%) among HIV-infected patients [30]. The analysis of determinants in the target groups showed that VC for seasonal influenza in 2010-2011 was related to previous vaccinations and the number of risk factors for severe influenza illnesses. This significant association between vaccine uptakes was shown previously [31].

Our study has both strengths and limitation that warrant discussion. First, the rate of participation (20\%) was slightly lower to those reported in previous studies of the Sentinelles network [32]. Probably, the main reason was that participating GPs were asked to fill the questionnaire for all patients presenting at their practice on a given day, which represented an important effort. In addition, summer holidays covered a large part of the data collection period. However, besides response rate, comparison of respondents to the whole population of Sentinel GPs did not show statistical differences neither on on socio-demographic data nor on type of practice. Second, general applicability of our results might be limited by the fact that the study was conducted in the specific population of French Sentinelles GPs. Comparison of our population to the whole population of French GPs did not show major differences neither on sociodemographic data nor on type of practice. However, the Sentinelles network is composed by volunteer GPs who collect real-time epidemiological data, suggesting a specific interest for public health, in particular for immunization. This limitation could explain the high vaccination rates observed, as compared to studies in 
general population. Third, since participation rate was relatively low, some target groups were less represented, leading to wide CI for rare target groups, in particular for HIV infection, other immunosupression, chronic renal disease and pregnancy. Patients of these categories probably get medical care from specialists of their chronic disease, hence underlining the importance of conducting specific studies in specialized medical services. And finally, immunization data were self-reported by the patient and/or the GPs and not writtenconfirmed, leading to some degree of imprecision in evaluation of the immunization status.

Despite these limitations, such studies among Sentinelles GPs can be complementary to the population-based studies. Indeed, our study allowed to collect data rapidly, on a large number of patients, and was resource-saving since all GPs of the Sentinel Network could easily and simulatenously be contacted via an automatic-generated email. If necessary, such study could be renewed yearly to follow variations of the $\mathrm{VC}$ from on year to another, for example in case of occurrence of an influenza pandemic. We also specifically described the characteristics of patients attending a medical consultation with French GPs, therefore it could help identify populations that could be counselled by their GPs to get vaccinated. In addition, such design might limit recall biases compared to telephone surveys. Indeed, estimation of VC was based both on answers of patients and on data collected by the GPs in their medical records. Usually, participation biases are in favor of better vaccinated individuals, leading to some over-estimation of coverage in the telephone surveys.

The prevalence of chronic conditions in our study sample was comparable to that estimated in the general population regarding data published by the French Ministry of Health [33] for pregnancy, obesity, diabetes mellitus, Sidainfection and chronic cardiac diseases (prevalence estimates of $1 \%, 13 \% 4 \%, 0.05 \%$ and $1 \%$ respectively in the general population). Persons aged 65 and over were overrepresented in our sample, whereas prevalence of chronic bronchopulmonary and renal diseases were low, maybe due to underdiagnosis. This confirms that for most chronic conditions, involvement of GPs can have a potentially important impact to improve VC. On the other hand, for patients with chronic bronchopulmonary and renal diseases, vaccination promotion limited to GP could be less efficient and specialists must be involved.

\section{Conclusions}

This study gives an overview of characteristics of patients seen on a given day in French general practices, as well as estimates of rates of immunization against both seasonal and pandemic influenza in target groups. Our estimates of $\mathrm{VC}$ are generally higher than that reported by others in the general population. GPs receive a very large proportion of patients targeted by vaccine recommendations (great variety of chronic underlying conditions and elderly persons). In addition, a lot of these patients are not regularly followed by other physicians who could offer vaccination (patients with obesity, diabetes...). We also report that pandemic influenza VC were lower than seasonal $\mathrm{VC}$ in all categories of patients. Contrary to a standard seasonal vaccination campaign, the administration of pandemic vaccine in 2009 in France was not primarily assured by GPs. This underlines the crucial role of GPs in promoting immunization in the community. There are some examples of successful public health measures through GP. Their involvement in colorectal cancer mass screening allows identification of high risk people who can then be managed with a more suitable screening protocol [34]. This study underlines the need to consider the role to be given to GPs in the choice and implementation of immunization strategies.

\section{Competing interests}

The authors declare that they have no competing interests.

\section{Authors' contributions}

LP conceived the design of the study, participated in acquisition and interpretation of data, and drafted the manuscript. AF participated in the design of the study, interpretation of data and helped to draft the manuscript. MLG participated in the design of the study, interpretation of data and statistical analysis. CS participated in the interpretation of data and drafting of the manuscript. CT participated in the design of the study, provided technical assistance on acquisition of data and helped to draft the manuscript. LF participated in the interpretation of data and drafting of the manuscript. TH participated in the design of the study, interpretation of data and helped to draft the manuscript. SK participated in the design of the study and interpretation of data, performed statistical analysis and helped to draft the manuscript. All authors read and approved the final manuscript.

\section{Acknowledgements}

We thank all GPs of the Sentinelles Network for their participation.

\section{Author details}

${ }^{1}$ INSERM, UMR-S 707, Paris F-75012, France. ' UPMC Université Paris 06, UMR-S U707, Paris F-75012, France. ${ }^{3}$ Laboratoire de Virologie, Université de Corse, France. ${ }^{4}$ Département des Maladies Infectieuses, Institut de Veille Sanitaire, Saint-Maurice, France. ${ }^{5}$ Réseau Sentinelles, U707 INSERM UPMC, faculté de médecine Saint-Antoine, 27 rue Chaligny, Paris Cedex 12 75571, France.

Received: 26 October 2012 Accepted: 11 March 2013

Published: 20 March 2013

\section{References}

1. Mereckiene J, Cotter S, D'Ancona F, Giambi C, Nicoll A, Lévy-Bruhl D, Lopalco PL, Weber JT, Johansen K, Dematte L, Salmaso S, Stefanoff P, Greco $D$, Dorleans F, Polkowska A, O'Flanagan D, on behalf of the VENICE project gatekeepers group: Differences in national influenza vaccination policies across the European Union, Norway and Iceland 2008-2009. Euro Surveill 2010, 15:pii=19700.

2. Institut de Veille Sanitaire: Calendrier des vaccinations et recommandations vaccinales 2009 selon l'avis du Haut conseil de la santé publique. BEH 2009, 16-17:148-149. http://www.invs.sante.fr/beh/ 2009/16_17/beh_16_17_2009.pdf.

3. Haut Conseil de Santé Publique, et al: Avis relatif à l'actualisation de la stratégie vaccinale contre la grippe 2010-2011. 2010:9. http://www.hcsp.fr/ docspdf/avisrapports/hcspa20101229_actuavacgrippe.pdf 
4. Tuppin P, Samson S, Weill A, Ricordeau P, Allemand H: Seasonal influenza vaccination coverage in France during two influenza seasons (2007 and 2008) and during a context of pandemic influenza $A(H 1 N 1)$ in 2009. vaccine 2011, 29:4632-4637.

5. Flahault A, Blanchon T, Dorléans Y, Toubiana L, Vibert JF, Valleron AJ: Virtual surveillance of communicable diseases: a 20-year experience in France. Stat Methods Med Res 2006, 15:413-421.

6. Institut national de la statistique et des études économiques: Définitions et méthodes.. http://www.insee.fr/fr/methodes/default.asp?page=definitions/ unite-urbaine.htm.

7. Institut national de prévention et d'éducation pour la santé: Baromètre santé médecins généralistes. 2009. http://www.inpes.sante.fr/CFESBases/catalogue/ pdf/1343.pdf.

8. Hanslik T, Espinoza P, Boelle PY, Cantin-Bertaux D, Gallichon B, Quendez S, Aïm JL, Retel O, Ballereau M, Gorodetzky N, Flahault A: Sentinel monitoring of general community health during the 1998 World Football Cup. Rev Epidemiol Sante Publique 2001, 49:135-145.

9. Tuppin P, Choukroun S, Samson S, Weill A, Ricordeau P, Allemand H: Vaccination against seasonal influenza in France in 2010 and 2011: Decrease of coverage rates and associated factors. Presse Med $2012 \mathrm{Nov}$ 41(11):e568-76.

10. Delelis-Fanien A-S, Séité F, Priner M, Paccalin M: Vaccine coverage against influenza and pneumococcal infections in patients aged 65 and over: a survey on 299 outpatients. Rev Med Interne 2009, 30:656-660.

11. Guthmann J-P, Fonteneau L, Bonmarin I, Lévy-Bruhl D: Influenza vaccination coverage one year after the $A(H 1 N 1)$ influenza pandemic, France, 2010-2011. Vaccine 2012, 30:995-997.

12. Aguilar I, Reyes M, Martínez-Baz I, Guevara M, Albéniz E, Belza MJ, Castilla J: Use of the vaccination register to evaluate influenza vaccine coverage in seniors in the 2010/11 influenza season, Navarre, Spain. Euro Surveill 2012, 17:pii=20154.

13. Takayama M, Wetmore CM, Mokdad AH: Characteristics associated with the uptake of influenza vaccination among adults in the United States. Prev Med 2012, 54:358-362.

14. Jiménez-García R, Hernández-Barrera V, Carrasco Garrido P, del Pozo SV-F, de Miguel AG: Influenza vaccination among cardiovascular disease sufferers in Spain: related factors and trend, 1993-2003. Vaccine 2006, 24:5073-5082

15. Singleton JA, Wortley P, Lu P-J: Influenza vaccination of persons with cardiovascular disease in the United States. Tex Heart Inst J 2004 31:22-27.

16. Mayo Montero E, Hernández Barrera V, Carrasco Garrido P, Gil De Miguel A, Jiménez García R: Influenza vaccination among persons with chronic respiratory diseases: coverage, related factors and time-trend, 1993-2001. Public Health 2007, 121:113-121.

17. Chiatti C, Barbadoro P, Marigliano A, Ricciardi A, Di Stanislao F, Prospero E: Determinants of influenza vaccination among the adult and older Italian population with chronic obstructive pulmonary disease: a secondary analysis of the multipurpose ISTAT survey on health and health care use. Hum Vaccin 2011, 7:1021-1025.

18. Jiménez-García R, Ariñez-Fernandez MC, Garcia-Carballo M, HernándezBarrera V, de Miguel AG, Carrasco-Garrido P: Influenza vaccination coverage and related factors among Spanish patients with chronic obstructive pulmonary disease. Vaccine 2005, 23:3679-3686.

19. Jiménez-García R, Jimenez I, Garrido PC, Hernández-Barrera V, de Andres AL, del Barrio $J$, de Miguel AG: Coverage and predictors of influenza vaccination among adults with diabetes in Spain. Diabetes Res Clin Pract 2008, 79:510-517.

20. Rodríguez-Rieiro C, Domínguez-Berjón MF, Esteban-Vasallo MD, SánchezPerruca L, Astray-Mochales J, Fornies DI, Ordoñez DB, Jiménez-García R: Vaccination coverage against 2009 seasonal influenza in chronically ill children and adults: analysis of population registries in primary care in Madrid (Spain). Vaccine 2010, 28:6203-6209.

21. Guthmann JP, Bone A, Nicolau J, Lévy-Bruhl D: Insuffisance de couverture vaccinale grippale $A(H 1 N 1) 2009$ en population générale et dans les groupes à risque durant la pandémie 2009-2010 en France. BEHWeb 2010, 3:1-6. http://www.invs.sante.fr/behweb/2010/03/a-1_2.htm.

22. Partouche $\mathrm{H}$, Benainous $\mathrm{O}$, Barthe J, Pierret J, Rigal L, Michaloux M, Gilberg S: A survey about determinants of 2009 pandemic influenza $A(H 1 N 1)$ vaccination among French general practionners patients. Motivac study Rev Prat 2011, 61:1411-1417.
23. Lin Y, Huang L, Nie S, Liu Z, Yu H, Yan W, Xu Y: Knowledge, attitudes and practices (KAP) related to the pandemic (H1N1) 2009 among Chinese general population: a telephone survey. BMC Infect Dis 2011, 11:128.

24. Ormen B, Türker N, Vardar I, Kaptan F, El S, Ural S, Kaya F, Coşkun NA: Attitudes and side effects related to pandemic influenza $A(H 1 N 1)$ vaccination in healthcare personnel. Mikrobiyol Bul 2012, 46:57-64.

25. Ahluwalia IB, Singleton JA, Jamieson DJ, Rasmussen SA, Harrison L: Seasonal influenza vaccine coverage among pregnant women: pregnancy risk assessment monitoring system. J Womens Health (Larchmt) 2011 20:649-651.

26. van Lier A, Steens A, Ferreira JA, van der Maas NAT, de Melker HE: Acceptance of vaccination during pregnancy: experience with 2009 influenza A (H1N1) in the Netherlands. Vaccine 2012, 30:2892-2899.

27. Blondel B, Mahjoub N, Drewniak N, Launay O, Goffinet F: Failure of the vaccination campaign against $A(\mathrm{H} 1 \mathrm{~N} 1)$ influenza in pregnant women in France: results from a national survey. Vaccine 2012, 30:5661-5665.

28. Wallis DH, Chin JL, Sur DKC, Lee MY: Increasing rates of influenza vaccination during pregnancy: a multisite interventional study. J Am Board Fam Med 2006, 19:345-349.

29. Gallagher KM, Juhasz M, Harris NS, Teshale EH: Predictors of influenza vaccination in HIV-infected patients in the United States, 1990-2002. J Infect Dis 2007, 196:339-346.

30. Cotte L, Voirin N, Richard C, Brochier C, Schlienger I, Lack P, Lina B, Vanhems $P$, Zoulim F: Factors associated with pandemic influenza $A / H 1 N 1$ vaccine coverage in a French cohort of HIV-infected patients. Vaccine 2011, 29:5638-5644

31. Vaux S, Van Cauteren D, Guthmann J-P, Le Strat Y, Vaillant V, de Valk H, Lévy-Bruhl D: Influenza vaccination coverage against seasonal and pandemic influenza and their determinants in France: a cross-sectional survey. BMC Public Health 2011, 11:30.

32. Falchi A, Lasserre A, Gallay A, Blanchon T, Sednaoui P, Lassau F, et al: A survey of primary care physician practices in antibiotic prescribing for the treatment of uncomplicated male gonoccocal urethritis. BMC Fam Pract 2011, 12(1):35.

33. Ministère de la Santé, de la Jeunesse, des Sports et de la Vie associative: Plan 2007-2011pour l'amélioration de la qualité de vie des personnes atteintes de maladies chroniques.. http://www.sante.gouv.fr/IMG/pdf/plan2007_2011. pdf

34. Desoubeaux N, Herbert C, Launoy G, Vallée JP, Bouvier V, Maurel J, Née E, Gignoux M: Mass screening of colorectal cancer by general practitioners in France: what is the real target population? Gastroenterol Clin Biol 1997, 21:760-763.

doi:10.1186/1471-2458-13-246

Cite this article as: Privileggio et al:: Rates of immunization against pandemic and seasonal influenza in persons at high risk of severe influenza illness: a cross-sectional study among patients of the French Sentinelles general practitioners. BMC Public Health 2013 13:246.

\section{Submit your next manuscript to BioMed Central and take full advantage of:}

- Convenient online submission

- Thorough peer review

- No space constraints or color figure charges

- Immediate publication on acceptance

- Inclusion in PubMed, CAS, Scopus and Google Scholar

- Research which is freely available for redistribution 